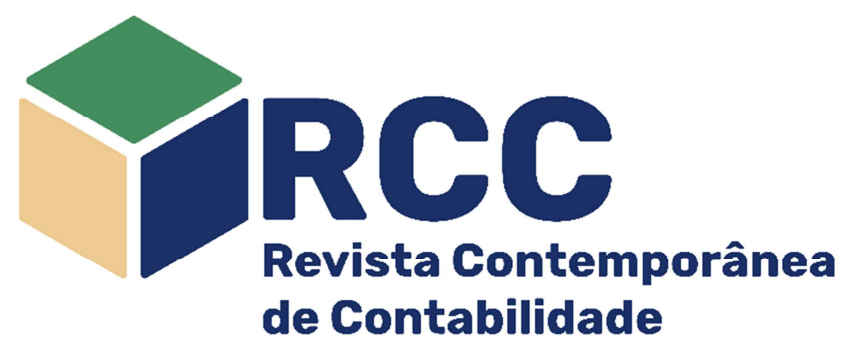

\title{
Análise das normas sociais no uso de entrevistas em artigos científicos em contabilidade no Brasil no período de 2010 a 2019
}

\author{
Analysis of social norms of interview-based papers in Brazilian accounting journals from 2010 to \\ 2019
}

\begin{abstract}
Análisis de las normas sociales en el uso de entrevistas en artículos científicos en contabilidad en Brasil en el período de 2010 a 2019
\end{abstract}

\author{
João Paulo Resende de Lima \\ Doutorando em Controladoria e Contabilidade (USP), \\ São Paulo/SP, Brasi \\ jp.resendelima@hotmail.com \\ https://orcid.org/0000-0002-4703-2603
}

Vanessa Ramos da Silva Doutoranda em Ciências Contábeis (UFU) Professora da UNIESSA, Uberlândia/MG, Brasil vanessaramossilva@hotmail.com https://orcid.org/0000-0001-8386-8048

Edvalda Araújo Leal

Doutora em Administração (FGV-SP) Professora do Programa de Pós Graduação e Graduação da Faculdade de Ciências Contábeis (UFU), Uberlândia-MG, Brasil edvalda@ufu.br

https://orcid.org/0000-0002-7497-5949 (i)

Endereço do contato principal para correspondência* Rua João Naves de Ávila, no 2121, Bairro Santa Mônica, CEP: 38408-100 - Uberlândia, MG, Brasil

\section{Resumo}

O presente estudo visa analisar o emprego de entrevistas na constituição de evidências na pesquisa contábil brasileira. Para tanto se adota a Sociologia do Conhecimento como aporte teórico. Como estratégia de pesquisa, foi elaborado um levantamento de artigos publicados entre os anos de 2010 e 2019 em oito periódicos científicos de Contabilidade classificados como A2, resultando numa amostra de 168 artigos. As categorias analisadas abordam as entrevistas como prática social conforme proposto por Dai, Free e Gendron (2019). Dentre os resultados destaca-se o baixo grau de transparência sobre o processo de realização da entrevista. O presente artigo contribui para a discussão epistemológica e metodológica acerca da pesquisa qualitativa aplicada à Contabilidade, especialmente, a pesquisa colabora com os pesquisadores interessados em conduzir entrevistas para que conheçam os principais critérios metodológicos indicados para a preparação, condução e interpretação.

Palavras-chave: Pesquisa Contábil; Pesquisa Qualitativa; Entrevista; Normas Sociais

\begin{abstract}
We aim to analyze the use of interviews in the data gathering process in Brazilian Accounting research. We rely upon Sociology of Knowledge as the theoretical framework. We gathered papers published between 2010 and 2019 in eight scientific journals of Accounting classified as A2, resulting in a sample of 168 papers. To analyze the data, we draw upon Dai, Free and Gendron (2019), who argues that interview-based papers rely upon social norms of the scientific community. Among the results, we highlight the low degree of transparency about the interviewing process. We hope to contribute epistemologically and methodologically to the discussion about accounting qualitative research. The research collaborates with researchers interested in conducting interviews to know the main methodological criteria indicated for the preparation, conduct, and interpretation.
\end{abstract}

Keywords: Accounting Research; Qualitative Research; Interview; Social Norms

\section{Resumen}

Nuestro objetivo es analizar el uso de las entrevistas en el proceso de recogida de datos en la investigación 
contable brasileña. Nos basamos en la Sociología del Conocimiento como marco teórico. Reunimos trabajos publicados entre 2010 y 2019 en ocho revistas científicas de Contabilidad clasificadas como A2, resultando en una muestra de 168 artículos. Para el análisis de los datos, nos basamos en Dai, Free y Gendron (2019), quien sostiene que los artículos basados en entrevistas se basan en las normas sociales de la comunidad científica. Entre los resultados, destacamos el bajo grado de transparencia sobre el proceso de entrevistas. Esperamos contribuir epistemológica y metodológicamente a la discusión sobre la investigación cualitativa contable. La investigación colabora con los investigadores interesados en realizar entrevistas para conocer los principales criterios metodológicos indicados para la preparación, realización e interpretación.

Palabras clave: Investigación contable; Investigación cualitativa; Entrevista; Normas Sociales

\section{Introdução}

Partindo do pressuposto teórico de que a realidade é socialmente construída destaca-se a importância de entender "a realidade interpretada pelos homens e subjetivamente dotada de sentido" (Berger \& Luckmann, 2014, p. 35). Nesse sentido, a pesquisa qualitativa auxilia no entendimento da construção dessa realidade, visto que a partir da pesquisa qualitativa pode-se entender os significados construídos pelos sujeitos sociais e como tais sujeitos apreendem a realidade (Merriam, 2002).

No caso da Contabilidade, assim como nas demais ciências sociais aplicadas, observa-se a evolução das pesquisas ao decorrer do tempo frente às diversas mudanças sociais e econômicas. No contexto brasileiro, a pesquisa contábil apresentou um expressivo enfoque normativo desde a década de 1970 até a década de 1990, quando passou a ser adotado um enfoque fortemente positivista com base nos métodos quantitativos (ludícibus, Martins, \& Carvalho, 2005; Martins, 2005). Apesar de a abordagem predominante nas pesquisas da área ainda ser a quantitativa, observa-se uma maior abertura para a pesquisa qualitativa (Ganz, Lima \& Haveroth, 2019; Merchant, 2010; Dyckman \& Zeff, 2015).

No mundo da pesquisa qualitativa, a construção do corpus a ser analisado pode se dar de diversas maneiras, entretanto, a mais utilizada tem sido as entrevistas (King, 2004; Qu \& Dumay, 2011), que pode ser conceituada como uma conversa entre pesquisador(a) e participante da pesquisa (Kvale, 2007). Dentre os motivos para o grande uso das entrevistas na pesquisa qualitativa, destacam-se sua flexibilidade e a possibilidade de aprofundamento (Creswell, 2015). Exatamente por seu caráter flexível, o uso de entrevistas tem levantado debates de cunho epistemológico e metodológico acerca de suas potencialidades, assim como seus perigos e devidos procedimentos éticos (King, 2004). Outra consequência da flexibilidade das entrevistas é o fato de não existirem regras para a sua condução e, dessa forma, cada comunidade científica estabelece o conjunto de práticas aceitas (Dai, Free \& Gendron, 2019).

O conjunto de práticas aceitas por esse grupo pode ser conceituado como "normas sociais", que podem ser definidas como um conjunto de "regras negociadas coletivamente de comportamento social, de costumes, tradições, padrões, regras, valores e todos os demais critérios de conduta, os quais são estabelecidos pelo contato entre os indivíduos" (Sherif, 1936, p.3). É importante ainda destacar que tais normas são influenciadas pela cultura daquele grupo e constitui um caráter normativo no sentido de guiar/punir aqueles que não as seguem (Pepitone, 1976; Veiga, Torres \& Bruno-Faria, 2013).

Considerando que as normas sociais são influenciadas pelos indivíduos que formam o grupo social e a cultura desse grupo, partimos do pressuposto que as normas encontradas por Dai, Free e Gendron (2019) serão diferentes das encontradas nos periódicos brasileiros. Uma das razões para tal é a diferença cultural entre os periódicos brasileiros e os periódicos de língua inglesa. Além disso, como apontado anteriormente a pesquisa qualitativa no Brasil encontra-se em estágio inicial devido a hegemonia da pesquisa positivista nos programas de pós-graduação da área e nos periódicos brasileiros. Nesse mesmo sentido, observa-se o alinhamento entre o conceito de "normas sociais" e a Sociologia do Conhecimento, visto que esse aporte teórico procura entender os processos por quais determinados conhecimentos são socialmente estabelecidos, dessa forma, "a sociologia do conhecimento deve ocupar-se com tudo aquilo que passa por 'conhecimento' em uma sociedade, independentemente da validade ou invalidade última (por quaisquer critérios) desse 'conhecimento'". (Berger \& Luckmann, 2014, p. 13).

Diante do contexto apresentado, o presente artigo visa analisar o emprego de entrevistas na constituição de evidências na pesquisa contábil brasileira, visando responder à pergunta: como pesquisadores e pesquisadores têm utilizado entrevistas para a constituição de evidências em pesquisas qualitativas publicadas nos principais periódicos de Contabilidade no Brasil? Dessa forma, tem-se como objeto de estudo as entrevistas empregadas nos artigos científicos analisados. Como objetivos específicos foram estabelecidos: (i) analisar a publicação de estudos qualitativos com entrevistas nos principais periódicos brasileiros em contabilidade; (ii) analisar as normas sociais acerca do uso das entrevistas na pesquisa contábil brasileira; (iii) analisar como as evidências constituídas por meio das entrevistas foram analisadas.

Como aporte teórico adota-se a Sociologia do Conhecimento juntamente com o conceito de normas sociais. Para a análise, foi adotado o trabalho de Dai, Free e Gendron (2019) como referencial metodológico, dessa forma, adotamos as seguintes categorias propostas pelos autores: linha de pesquisa, 
número de participantes no estudo, discussão sobre saturação teórica dos dados, número de citações do conteúdo das entrevistas. Adicionalmente, ainda foram analisados se o estudo era qualitativo ou de método misto, se havia menção ao processo de construção do guia de entrevistas, verificados os detalhes acerca da duração e realização das entrevistas, o motivo para escolha dos participantes e, por fim, se o estudo apresenta os procedimentos éticos relacionados à pesquisa, como o Termo de Consentimento Livre e Esclarecido ou submissão do projeto a comitê de ética.

Especificamente, na pesquisa contábil brasileira, a discussão acerca das práticas do uso de entrevistas faz-se necessária devido ao pouco treinamento específico para o uso de métodos qualitativos destinados aos pesquisadores(as) da área, tendo em vista as poucas disciplinas relacionadas a métodos qualitativos oferecidas nos programas de pós-graduação (Martins, 2012; Ganz, Lima \& Haveroth, 2019). O trabalho justifica-se ainda pela potencialidade das entrevistas de contribuir para 0 avanço da pesquisa contábil, pela possibilidade de apreender a realidade das empresas e profissionais contábeis, e pelo considerável número de artigos que utilizam as entrevistas para construção de evidências. Por fim, observam-se poucos estudos acerca das normas sociais que permeiam a academia contábil brasileira.

Para atingir o objetivo proposto, foi realizado um levantamento de artigos que utilizam a condução de entrevistas para a composição de seu corpus. Assim, foram analisados oito periódicos brasileiros de Contabilidade, considerados de alto impacto, no período de 2010 a 2019. A partir desse levantamento, foram encontrados 168 artigos que adotaram entrevistas para a coleta de dados. Os resultados mostram que as práticas brasileiras diferem das práticas adotadas nos periódicos de língua inglesa, principalmente, no que se refere ao número de entrevistas e trechos das entrevistas utilizados para a análise dados.

A partir desses resultados, o presente artigo contribui para a discussão epistemológica e metodológica acerca da pesquisa qualitativa aplicada à Contabilidade. Ao aprofundar a discussão sobre aspectos metodológicos para a preparação e condução de entrevistas, o presente artigo apresenta ainda potencial para contribuir com pesquisadores(as) que tenham interesse em conduzir entrevistas para suas pesquisas. $O$ artigo tem potencial de contribuir com autores, editores e avaliadores de periódicos ao apresentar e discutir as práticas sociais em torno das entrevistas na perspectiva da comunidade brasileira. Por fim, é importante destacar que a presente pesquisa não visa construir e apresentar um check-list de como se publicar uma pesquisa cujo corpus foi constituído por entrevistas.

\section{Referencial Teórico}

O presente trabalho ancora-se teoricamente na Sociologia do Conhecimento que possui como questão central a discussão acerca do "conhecimento" e da "realidade", sendo conhecimento considerado "como a certeza de que os fenômenos são reais e possuem características específicas" e realidade "uma qualidade pertencente a fenômenos que reconhecemos terem um ser independente de nossa própria volição" (Berger \& Luckmann, 2014, p. 11).

Um dos princípios fundantes da Sociologia do Conhecimento é o fato de que a realidade é socialmente construída, dessa forma, cada sociedade define o que é admitido como conhecimento para si. A partir desse princípio, a Sociologia do Conhecimento trata "dos processos pelos quais qualquer corpo de "conhecimento" chega a ser socialmente estabelecido como 'realidade'” (Berger \& Luckmann, 2014, p. 13).

A partir dessa abordagem teórica, observa-se a importância da discussão acerca das concepções de "realidade" e do "conhecimento" para a sociedade de maneira geral e para a pesquisa acadêmica, visto que tais concepções são os pressupostos filosóficos das abordagens de pesquisa que conhecemos hoje como quantitativa e qualitativa, além de fundar as tradições de pesquisa - também chamadas de paradigmas. É nesse contexto ainda que os métodos de pesquisa se inserem como forma de apreender a realidade social e em alguns casos tentar intervir nessa realidade (Crotty, 1998; Gephart, 2004).

Tais pressupostos filosóficos são expressos pela ontologia e pela epistemologia que relacionam ao processo de criação do conhecimento às crenças acerca da realidade na qual o conhecimento é gerado (Crotty, 1998; Martins, 2012). De maneira geral, a ontologia pode ser definida como o estudo dos seres e a natureza de sua existência (Crotty, 1998) e se baseia na discussão do que é a realidade e como tal se constitui (Ryan, Scapens \& Theobold, 2002), ao passo que a epistemologia diz respeito a como adquirimos conhecimentos (Ryan, Scapens \& Theobold, 2002).

Apesar de a discussão sobre escolhas e posições ontológicas e epistemológicas serem usualmente ignoradas ou negligenciadas nas pesquisas em contabilidade (Martins, 2012; Ganz, Lima \& Haveroth, 2019) a coerência entre tais escolhas é de suma importância para a realização de uma pesquisa com maior profundidade e impacto. Ressalta-se ainda que diferentes posições ontológicas e epistemológicas levam a diferentes caminhos teóricos e metodológicos (Chua, 1986; Gephart, 2004), além de representar diferentes tradições de pesquisa.

A combinação de diferentes elementos ontológicos e epistemológicos dá base ao que alguns autores - como Burrel e Morgan (1979), Martins (2012) e Saccol (2009) - chamam de paradigma ou de tradição de pesquisa (Gephart, 2004). As principais tradições de pesquisa na área de negócios são: o Positivismo, o Pós-Positivismo, o Interpretativismo e a pesquisa Crítica. Apesar de usualmente a pesquisa qualitativa ser relacionada ao Interpretativismo e à pesquisa Crítica não são raros os exemplos de pesquisa 
Positivista e Pós-Positivista com métodos qualitativos na área de administração e contabilidade (Gephart, 2004; Major, 2017), ao mesmo passo que crescem os trabalhos quantitativos na pesquisa Crítica (Richardson, 2015).

Nesse contexto, observa-se a importância da coerência entre os diversos elementos que constituem uma pesquisa e que devem ser pensados antes da escolha da abordagem quantitativa ou qualitativa. Postas as diferenças filosóficas entre as duas abordagens, faz-se oportuno apresentar algumas definições entre elas.

A abordagem quantitativa de pesquisa visa testar teorias objetivas ao examinar a relação entre diversas variáveis, bem como costuma adotar uma lógica dedutiva e busca a máxima objetividade e controle contra vieses (Creswell \& Creswell, 2018). A coleta de dados nessa abordagem de pesquisa pode ocorrer de diversas maneiras: baseada em questionários ou levantamentos (Diehl \& Tatim, 2004), construção de bases de dados primárias, uso de bases de dados já existentes ou bases secundárias, como Economatica, Compustat etc. (Smith, 2003), dentre outras maneiras. As análises realizadas nessa abordagem vão desde estatísticas descritivas a técnicas estatísticas, econométricas e matemáticas, as quais são tidas como mais robustas.

Já a abordagem qualitativa de pesquisa visa explorar e compreender os significados construídos pelas pessoas ou grupos de pessoas acerca de problemas sociais (Creswell \& Creswell, 2018). Tal abordagem de pesquisa consiste em um conjunto de práticas interpretativas que transformam a realidade em uma série de representações, bem como envolve uma abordagem naturalística e interpretativa do mundo (Denzin \& Lincoln, 2005). Nessa abordagem, as estratégias mais utilizadas no campo das ciências sociais são a pesquisa narrativa, fenomenologia, etnografia, grounded theory e o estudo de caso (Creswell, 2012).

As evidências para a abordagem qualitativa de pesquisa podem ser constituídas de diversas maneiras, tais como, observação participante e não participante (Serva \& Jaime, 1995), pesquisa documental (Hardy, 2001), diários reflexivos (Zaccarelli \& Godoy, 2014) e por meio de entrevistas (King, 2004; Dai, Free \& Gendron, 2019). As análises dessas evidências podem ocorrer com o uso, por exemplo, de análise de conteúdo (Mayring, 2000), análise do discurso (Godoi, 2010), análise de conversação (Flick, 2013), análise narrativa (Pentland, 1999), análise crítica do discurso (Foucault, 2008), análise etnográfica (Jaime Junior, 2003) e autoetnográfica (Haynes, 2006, Malsch \& Tessier, 2015), dentre outras.

Considerando a pesquisa em contabilidade, observa-se um claro predomínio da pesquisa quantitativa, tanto na literatura internacional (Merchant, 2010; Dyckman \& Zeff, 2015) quanto na literatura nacional, contudo é notável o crescente número de estudos qualitativos (Malsch \& Salterio, 2016; Dai, Free \& Gendron, 2019). Considerando a pluralidade e a flexibilidade da pesquisa qualitativa, nota-se um conjunto de regras formais e informais a serem seguidas, assim como o predomínio das entrevistas como principal método de construção de evidências (King, 2004; Dai, Free \& Gendron, 2019).

Assim, torna-se relevante um aprofundamento na caracterização da pesquisa qualitativa e, principalmente, evidenciar os principais critérios a serem observados para o rigor e qualidade no processo da pesquisa cientifica.

\subsection{Qualidade em Pesquisas Qualitativas}

Como discutido anteriormente, uma das preocupações da Sociologia do Conhecimento é o entendimento de como alguns conhecimentos são construídos socialmente como válidos, enquanto outros são tidos como inválidos. Nesse sentido, cada comunidade define seus princípios de qualidade para diferenciar um conhecimento válido de um inválido (Berger \& Luckmann, 2014) e sendo a realidade socialmente construída tais princípios se tornam "normas sociais" daquela comunidade (Veiga, Torres \& Bruno-Faria, 2013).

No contexto da pesquisa contábil, são adotadas diferentes tradições de pesquisa, tendo cada uma delas seus próprios pressupostos filosóficos, sendo necessário, portanto, entender que os critérios de qualidade e validade de cada pesquisa varia de acordo com a tradição de pesquisa adotada, visto que cada tradição de pesquisa entende "realidade" (ontologia) e "conhecimento" (epistemologia) de maneiras diferentes. No caso das pesquisas positivistas e quantitativas, os parâmetros de qualidade são mais conhecidos, sendo os principais parâmetros a validade e a confiabilidade, estando ambos relacionados à capacidade de generalização estatística dos resultados (Smith, 2003).

$\mathrm{Na}$ pesquisa qualitativa, também são adotados critérios de qualidade, entretanto, tais critérios possuem diferentes contornos devido à sua subjetividade e pressupostos filosóficos. Stenbacka (2001) apresenta quatro critérios de qualidade para avaliar uma pesquisa qualitativa: validade, confiabilidade, generalização e cuidado. O primeiro critério apresentado por Stenbacka (2001) refere-se à validade, que pode ser adereçada com base nos respondentes da pesquisa uma vez que o intuito dessa abordagem é entender a realidade social sob uma ótica específica. Assim, para avaliar a validade de um estudo qualitativo, questiona-se: "Os participantes da pesquisa estão envolvidos no fenômeno estudado?". Em relação à aplicação do conceito de confiabilidade, a autora afirma que, na pesquisa qualitativa, refere-se ao processo de descrição detalhado da pesquisa, permitindo que os(as) leitores(as) entendam todas as 
escolhas tomadas no decorrer da pesquisa.

Uma das críticas relacionadas à pesquisa qualitativa relaciona-se ao terceiro critério de qualidade apontado por Stenbacka (2001), ou seja, a generalização. A discussão acerca da generalização dos resultados permeia profundamente os trabalhos quantitativos e interferem na escolha de amostra e da população, além dos métodos de análise, contudo tal discussão baseia-se no poder de generalização estatística dos resultados. Para as pesquisas qualitativas, esse conceito também pode ser aplicado, entretanto a generalização dos resultados é chamada de "generalização analítica" (Yin, 2009) ou "generalização teórica" (Mattos, 2011) devido aos pressupostos filosóficos e à natureza da abordagem qualitativa. Por fim, o critério "cuidado" relaciona-se ao rigor da condução da pesquisa e da consciência que o(a) pesquisador(a) tem de sua subjetividade e influência no processo da pesquisa e construção do conhecimento. Além dos conceitos apresentados por Stenbacka (2001), outros autores propõem diversos critérios alternativos, sendo alguns deles apresentados na Figura 1.

\begin{tabular}{|c|c|}
\hline $\begin{array}{c}\text { Critérios de Qualidade } \\
\text { Relevância; Validade filosófica e metodológica; Lógica interna; Aplicabilidade } \\
\text { empírica }\end{array}$ & Base Teórica \\
\hline $\begin{array}{c}\text { Confiabilidade; Conformidade; (1979) } \\
\text { teórica }\end{array}$ & Lincoln e Guba (1985) \\
\hline Validade contextual; Transferibilidade; Confiabilidade processual & Ryan et al. (2002) \\
\hline Convencimento: Autenticidade; Plausibilidade; Criticamente & Golden-Biddle e Locke (1993) \\
\hline Utilidade (prática) & $\begin{array}{c}\text { Golden-Biddle e Locke (1993), } \\
\text { Lillis (2006) e Mäkinen (1980) }\end{array}$ \\
\hline Generalização contextual; Generalização construtiva & Yasanen (1995) \\
\hline Generalização analítica & Eriksson e Kovalainen, (2008) \\
\hline Coerência; Consistência; Utilidade; Resultados estendidos para um contexto mais \\
amplo
\end{tabular}

Figura 1 - Critérios de Qualidade aplicados à pesquisa qualitativa

Fonte: Traduzido e adaptado de Kihn e Ihantola (2015)

Além dos critérios apresentados na Figura 1, emergiu, mais recentemente, a discussão acerca da reflexividade do/da pesquisador/pesquisadora. Tal discussão se relaciona ao processo de construção do conhecimento e aos vieses e características do/da pesquisador/pesquisadora (Paiva Junior, Leão \& Mello, 2011; Berger, 2015; Dambrin \& Lambert, 2012). Especificamente, no caso das entrevistas, objeto de análise do presente estudo, existem critérios específicos para suas análises. No próximo tópico, apresentam-se as principais características e práticas sociais que são adotadas na condução e análise de entrevistas nas pesquisas científicas.

\subsection{Entrevistas}

O uso de entrevistas é uma das principais maneiras de constituir evidências na pesquisa qualitativa, independentemente da estratégia de pesquisa (King, 2004; Qu \& Dumay, 2011). A entrevista pode ser conceituada como uma conversa cuja estrutura é definida, a priori, por uma das partes envolvidas - 0 entrevistador/a entrevistadora - (Kvale, 2007). Apesar de ser amplamente utilizada para obter um bom resultado, é preciso que o(a) pesquisador(a) esteja bem-preparado para o uso das entrevistas (Hannabuss, 1996) e detenha as habilidades e as competências necessárias para a aplicação do método (Rubin \& Rubin, 2012).

O propósito de qualquer entrevista é analisar o fenômeno objeto de estudo a partir da perspectiva do participante da pesquisa, visto que a entrevista busca juntar descrições de mundo que busquem a interpretação dos significados construídos pelas pessoas (King, 2004; Kvale, 2007; Qu \& Dumay, 2011). A entrevista distingue-se da aplicação de questionários, principalmente, pelo fato de que a pessoa que está participando é vista como um respondente e não como um objeto de pesquisa, além da maior liberdade que o(a) pesquisador(a) tem para fazer novas perguntas de acordo com o contexto e as novas informações que surgem (King, 2004; Kvale, 2007; Qu \& Dumay, 2011). Para atingir o propósito, existem diferentes tipos/abordagens de entrevista, como a entrevista em profundidade, estruturada, semiestruturada, desestruturada, exploratória etc. (King, 2004), estando os principais tipos de entrevista apresentados na Figura 2.

É importante ressaltar que os tipos de entrevista apresentados na Figura 2 referem-se à entrevista de maneira geral e não abrangem as diversas modalidades e abordagens que existem, assim como suas particularidades e sutilezas desde a preparação até a análise. Dentre as possibilidades, podem ser destacadas a entrevista etnográfica (Schensul \& Lecompte, 2012), a entrevista narrativa (Muylaert, Sarubbi JR, Gallo, Neto, \& Reis, 2014), a entrevista com abordagem de história de vida (Haynes, 2010; Godoy, 2018), a entrevista fenomenológica (Seidman, 2006; Soares Neto \& Silva, 2012), dentre outras. 


\begin{tabular}{|c|c|c|}
\hline $\begin{array}{c}\text { Tipo de } \\
\text { Entrevista }\end{array}$ & Descrição & $\begin{array}{c}\text { Sugestão de } \\
\text { Leituras }\end{array}$ \\
\hline Estruturada & $\begin{array}{l}\text { Esse tipo de entrevista consiste na construção de um roteiro de entrevista } \\
\text { em que todas as perguntas já são pré-estabelecidas. Todos os/as } \\
\text { participantes da pesquisa respondem exatamente as mesmas perguntas e, } \\
\text { assim, o nível de flexibilidade para aprofundar novos assuntos que possam } \\
\text { surgir é bem baixo. As entrevistas estruturadas costumam ser utilizadas } \\
\text { quando a pesquisa exige uma visão mais neutra do/da } \\
\text { pesquisador/pesquisadora e visa a um maior poder de generalização. Um } \\
\text { dos principais pressupostos dessa entrevista é de que, se a pergunta for } \\
\text { feita de maneira adequada, a resposta será completa e honesta, revelando a } \\
\text { verdade do/da participante da pesquisa. Caracteriza-se por utilizar um } \\
\text { roteiro de entrevistas rígido e igual para todos os participantes da pesquisa. }\end{array}$ & $\begin{array}{c}\text { Fontana e Frey } \\
(1998) \\
\text { Berg (1998) } \\
\text { Doyle (2004) } \\
\text { Qu e Dumay (2011) } \\
\text { Lune e Berg (2017) }\end{array}$ \\
\hline Semiestruturada & $\begin{array}{c}\text { Encontra-se no meio do continuum das entrevistas estruturadas e } \\
\text { desestruturadas. É usualmente o tipo de entrevista mais utilizado nas } \\
\text { pesquisas na área de negócios. Esse tipo de entrevista consiste em uma } \\
\text { série de perguntas construídas previamente pelo/pela } \\
\text { pesquisador/pesquisadora, contudo permite aprofundamento de novos } \\
\text { assuntos conforme tais assuntos forem surgindo. Suas principais vantagens } \\
\text { são a flexibilidade, a acessibilidade e a inteligibilidade. Caracteriza-se por } \\
\text { utilizar um guia de entrevistas flexível que permite aprofundar novos temas, } \\
\text { conforme forem emergindo, com a utilização de questões complementares } \\
\text { (probe questions). }\end{array}$ & $\begin{array}{c}\text { Kvale (1983) } \\
\text { King (2004) } \\
\text { Qu e Dumay (2011) } \\
\text { Rubin e Rubin } \\
(2012) \\
\text { Mclntosh e Morse } \\
(2015) \\
\text { Lune e Berg (2017) }\end{array}$ \\
\hline Desestruturada & $\begin{array}{c}\text { A entrevista desestruturada parte do princípio de que o/a } \\
\text { entrevistador/entrevistadora não sabe, a priori, todas as perguntas } \\
\text { necessárias para atingir seu propósito de pesquisa, devendo, assim, seguir } \\
\text { o fluxo de informações que o/a participante da pesquisa fornecer no decorrer } \\
\text { da entrevista. Devido ao seu caráter aberto, o/a pesquisador/pesquisadora } \\
\text { deve se preparar para situações não esperadas. Para alguns } \\
\text { pesquisadores, esse é o tipo de entrevista mais poderoso, visto que deixa } \\
\text { o/a participante da pesquisa à vontade, relaxado e sem se sentir sendo } \\
\text { avaliado/analisado. Caracteriza-se pelo uso de um guia de entrevistas com } \\
\text { poucas questões que tratam temas abrangentes que incentivam os/as } \\
\text { participantes a falarem sobre eles. }\end{array}$ & $\begin{array}{c}\text { Greene (1998) } \\
\text { Douglas (1985) } \\
\text { Qu e Dumay (2011) } \\
\text { Rubin e Rubin } \\
(2012) \\
\text { Lune e Berg (2017) }\end{array}$ \\
\hline
\end{tabular}

Figura 2 - Tipos de Entrevista

Fonte: Elaboração própria com base em Kvale (1989, 2007); Gubrium et al. (2012); Qu \& Dumay (2011).

Outro ponto a ser considerado, ao discutir as diversas maneiras e possibilidades de se realizarem entrevistas, é o impacto das Tecnologias da Informação e Comunicação (TICs) (O'connor, 2004; O'Connor, Madge, Shaw \& Wellens, 2008). Antes da popularização da internet, a realização de entrevistas limitava-se ao uso de ligações por telefone - que não possibilitava o contato visual entre pesquisador(a) e participante - ou pessoalmente (Morgan \& Symon, 2004; Seitz, 2016), o que dificultava a realização de pesquisas com participantes de outras localidades ou de difícil acesso. Dentre os benefícios trazidos por softwares que possibilitam ligações de áudio e vídeo, como o Skype, destacam-se a facilidade de realizar a entrevista em um local seguro e sem deslocamento (Hanna, 2012), bem como o aumento do número de participantes devido à facilidade da realização das entrevistas (Deaking \& Wakefield, 2014).

Apesar das claras vantagens trazidas pelo uso das TICs, existem pesquisadores que questionam até que ponto as entrevistas feitas por meio eletrônico têm a mesma profundidade e validade que as entrevistas realizadas pessoalmente (Seitz, 2016). Tais discussões baseiam-se no fato de que a pesquisa qualitativa tem nuances subjetivas relacionadas à linguagem corporal (Hay-Gibson, 2009), além da influência exercida pelo ambiente criado pelo(a) pesquisador(a) para a sua condução (Opdenakker, 2006).

Independentemente da abordagem, do tipo e da maneira com que a entrevista será realizada, é consenso na literatura, como mostrado anteriormente, a importância da preparação do(a) pesquisador(a). Um dos principais - talvez, o principal - preparativos para a realização da entrevista é a construção do guia ou roteiro de entrevista. No presente trabalho, a diferenciação entre guia e roteiro é estabelecida com base no grau de liberdade e flexibilidade, visto que um guia não precisa ser seguido à risca e palavra a palavra, ao contrário do que ocorre no roteiro de entrevista (King, 2004; Qu \& Dumay, 2011).

King (2004) sugere três passos que antecedem a entrevista: (i) definir o problema de pesquisa, (ii) construir o guia da entrevista e (iii) recrutar os participantes. Segundo o autor, ao definir o problema de pesquisa, deve-se focar em como os participantes descrevem e dão sentido às suas experiências. Para a construção do guia/roteiro de entrevistas, King (2004) sugere que sejam consultadas três fontes: a literatura existente sobre o tema, a experiência do(a) pesquisador(a) e, por fim, uma troca de experiências com pesquisadores(as) com mais conhecimento sobre o tema pesquisado. Além disso, o recrutamento dos participantes deve ser sempre intencional e relacionado ao problema de pesquisa.

Além dos passos sugeridos por King (2004), é importante discutir um aspecto essencial na pesquisa qualitativa, que é o acesso ao campo e aos participantes, o que é, talvez, o aspecto mais importante da 
pesquisa qualitativa, principalmente, nas pesquisas etnográficas, pois, sem acesso ao campo, a realização da pesquisa é inviabilizada. Cunliffe e Alcadipani (2016) afirmam que o acesso ao campo pode ser definido de diversas maneiras e em diferentes níveis. Nesse sentido, ao obter permissão de entrada no campo, o mínimo que se pode esperar é o acesso para realizar entrevistas com pessoas selecionadas pela própria empresa, bem como as observações de curto prazo, podendo também ocorrer que a empresa proporcione total abertura a todas as informações e pessoas.

$\mathrm{O}$ acesso aos participantes pode ocorrer de diversas maneiras, tal como, por e-mail, redes sociais, pessoalmente ou por indicação (caracterizada pela técnica de snowballing). Existem ainda pesquisadores(as) que oferecem recompensas para incentivar a participação de mais pessoas na pesquisa, como é o caso de Silva (2015) que, visando aumentar o engajamento de participantes em sua pesquisa, oferecia duas horas de consultoria contábil em troca da participação. É preciso ainda destacar que a prática de oferecer recompensas e/ou sorteio de recompensas nem sempre é aceita pelos Comitês de Ética em Pesquisa das universidades.

Outro ponto importante no planejamento e realização de uma pesquisa qualitativa, assim como qualquer outra pesquisa que envolva interação com pessoas e demais seres vivos, se trata dos aspectos éticos. Creswell e Creswell (2018) sugerem que as questões éticas sejam divididas de acordo com a etapa da pesquisa, sugerindo ainda que, ao planejar o trabalho de campo, o(a) pesquisador(a) conheça o código de ética de sua profissão e de sua universidade, além de submeter o projeto para apreciação em comitês e comissões de ética institucionais em suas universidades de origem. Por sua vez, Eysenbach e Till (2001) e Orb, Eisenhauer e Wynaden (2001) destacam a importância do sigilo e do anonimato envolvidos na pesquisa qualitativa.

Como discutido até o momento a técnica de entrevistas possui diversas nuances que podem influenciar o processo de pesquisa e por tal motivo é importante refletir sobre o potencial das entrevistas para o objetivo de pesquisa. No campo da Contabilidade, por exemplo, as entrevistas permitem ir além das práticas observáveis e recuperar informações acerca de fenômenos não mensuráveis (Mahama \& Khalifa, 2017). Exemplos de pesquisa com base em entrevistas são encontrados em todas as áreas da Contabilidade. Na área Contabilidade Financeira observa-se o trabalho de Barreto, Murcia e Lima (2012) que analisaram a percepção de especialistas acerca do impacto do valor justo na crise financeira; em Contabilidade Gerencial o trabalho de Espejo e Von Eggert (2017) que analisaram a implantação de um departamento de controladoria; e em Ensino e Pesquisa em Contabilidade o trabalho de Lima e Araujo (2019) que analisaram o processo de construção da identidade docente dos docentes em Contabilidade. Destaca-se ainda o trabalho de Horton, Macve e Struyven (2004) que fazem reflexões sobre o processo de pesquisa com entrevistas na Contabilidade no contexto do Reino Unido e União Européia, destacando possibilidades e desafios dessa abordagem da pesquisa.

A partir da discussão apresentada entende-se a entrevista como um ato interacional entre sujeitos que visa compreender/apreender uma determinada realidade social. Dado seu caráter subjetivo cada comunidade tem seu próprio conjunto de "normas sociais" para definir se o conhecimento construído por aquela interação social deve ser considerado válido ou não destacando a importância de entender as normas de cada uma das comunidades em o pesquisador/a pesquisadora pretende se inserir. Nesse sentido, Dai, Free e Gendron (2019) analisaram as normais sociais da comunidade acadêmica de língua inglesa a partir de 639 artigos publicados no período de 2000 a 2014 em sete periódicos de alto impacto. Os resultados encontrados sugerem que o número médio de entrevistas para o artigo ser aceito é por volta de 26, que a noção de saturação teórica para a parada de entrevistas e idas ao campo é raramente mencionada, além de um aumento significativo no tamanho da seção de metodologia dos trabalhos, um aumento significativo no detalhamento do processo de codificação e análise dos dados, além do aumento de citações diretas das entrevistas.

\section{Procedimentos Metodológicos}

Visando alcançar o objetivo de analisar como os artigos científicos brasileiros publicados nos principais periódicos na área de contabilidade têm utilizado o emprego de entrevistas na constituição e análise de evidências, a presente pesquisa adotou a abordagem qualitativa. Para a realização do levantamento de dados e construção do corpus, foram adotados os quatro parâmetros sugeridos por Lima e Mioto (2007): temático, linguístico, cronológico e as fontes. Assim, foi definido que o parâmetro temático seria o emprego de entrevistas. Quanto ao linguístico, foram adotados os idiomas português, inglês e espanhol, visto que são os mais aceitos e publicados pelos periódicos brasileiros. Em relação ao parâmetro cronológico, adotou-se o intervalo de 2010 a 2019, abrangendo assim um período de dez anos, sendo tal período escolhido para que fosse possível refletir o estado das artes da área de maneira adequada. Alguns autores discutem que tal intervalo pode variar em até cinco anos (Huff, 1999; Pagliarussi, 2018).

Finalmente, acerca das fontes de dados, definiu-se que seriam utilizados os periódicos voltados para a pesquisa contábil com classificação A2 na avaliação do Qualis Capes de 2013 a 2016, sendo tal classificação a mais alta para os periódicos nacionais. Dessa forma, foram analisados os periódicos de maior impacto na área. Importante destacar que os oito periódicos selecionados são também indicados pela 
Associação Nacional de Programas de Pós Graduação em Ciências Contábeis (AnpCont). Assim, foram reunidos 168 artigos para análise, sendo a distribuição por periódico e por ano apresentada na Tabela 1.

Tabela 1:

Composição do corpus da pesquisa

\begin{tabular}{c|c|c|c|c|c|c|c|c|c|c|c}
\hline Periódico & $\mathbf{2 0 1 0}$ & $\mathbf{2 0 1 1}$ & $\mathbf{2 0 1 2}$ & $\mathbf{2 0 1 3}$ & $\mathbf{2 0 1 4}$ & $\mathbf{2 0 1 5}$ & $\mathbf{2 0 1 6}$ & $\mathbf{2 0 1 7}$ & $\mathbf{2 0 1 8}$ & $\mathbf{2 0 1 9}$ & TOTAL \\
\hline $\begin{array}{c}\text { Revista de Contabilidade \& Finanças } \\
\text { (RC\&F) }\end{array}$ & 1 & 1 & 1 & 0 & 1 & 1 & 1 & 1 & 1 & 1 & 9 \\
\hline $\begin{array}{c}\text { Revista de Contabilidade \& } \\
\text { Organizações (RCO) }\end{array}$ & 3 & 4 & 2 & 1 & 2 & 2 & 2 & 2 & 1 & 3 & 22 \\
\hline Contabilidade Vista \& Revista & 0 & 2 & 1 & 1 & 2 & 0 & 2 & 1 & 3 & 0 & 12 \\
\hline Revista Universo Contábil (RUC) & 3 & 1 & 3 & 4 & 2 & 2 & 2 & 4 & 1 & 0 & 22 \\
\hline $\begin{array}{c}\text { Revista Contemporânea de } \\
\text { Contabilidade (RCC) }\end{array}$ & 0 & 2 & 1 & 2 & 2 & 1 & 1 & 2 & 2 & 1 & 14 \\
\hline $\begin{array}{c}\text { Advances in Scientific and Applied } \\
\text { Accounting (ASAA) }\end{array}$ & 0 & 0 & 0 & 0 & 0 & 0 & 0 & 0 & 0 & 1 & 01 \\
\hline Brazilian Business Review (BBR) & 1 & 4 & 5 & 3 & 3 & 3 & 6 & 10 & 6 & 1 & 42 \\
\hline $\begin{array}{c}\text { Revista Brasileira de Gestão de } \\
\text { Negócios (RBGN) }\end{array}$ & 2 & 3 & 5 & 7 & 5 & 5 & 5 & 8 & 2 & 4 & 46 \\
\hline TOTAL & $\mathbf{1 0}$ & $\mathbf{1 7}$ & $\mathbf{1 8}$ & $\mathbf{1 8}$ & $\mathbf{1 7}$ & $\mathbf{1 4}$ & $\mathbf{1 9}$ & $\mathbf{2 8}$ & $\mathbf{1 6}$ & $\mathbf{1 1}$ & $\mathbf{1 6 8}$ \\
\hline Fonte: Dados da Pesquisa
\end{tabular}

Fonte: Dados da pesquisa

A coleta dos dados ocorreu entre os meses de dezembro de 2019 e janeiro de 2020. Para esse processo, foram acessados os websites dos periódicos e pesquisados os termos "entrevistas", "entrevista" e "qualitativa" contidos nos títulos e resumos dos trabalhos.

Para a análise, foram lidas as seções de metodologia e resultados dos artigos escolhidos, bem como foram utilizadas as categorias que moldam as entrevistas como prática social propostas por Dai, Free e Gendron (2019): linha de pesquisa, número de participantes no estudo, discussão sobre saturação teórica dos dados, número de citações do conteúdo das entrevistas. Além dessas categorias, ainda foi observado se o estudo era qualitativo ou de método misto, se havia menção ao processo de construção do guia de entrevistas, verificados os detalhes acerca da duração e realização das entrevistas, o motivo para escolha dos participantes e, por fim, se o estudo apresenta os procedimentos éticos relacionados à pesquisa, como o Termo de Consentimento Livre e Esclarecido ou submissão do projeto a comitê de ética.

\section{Análise e Discussão de Resultados}

Conforme apresentado na seção que trata da metodologia, foram selecionados 168 artigos que utilizaram entrevistas no processo de coleta de dados. Os trabalhos foram coletados em oito periódicos classificados em A2 pelo Qualis Capes. Primeiramente, foi identificada a classificação dos trabalhos por linha de pesquisa, o que revelou que a linha de pesquisa com maior número de trabalhos (51) foi Contabilidade Gerencial. Os outros trabalhos pertencem às seguintes linhas: Ensino e Pesquisa em Contabilidade; Contabilidade Financeira; Contabilidade Pública; Contabilidade Ambiental e Sustentabilidade; e Auditoria e Perícia. Foram identificados também trabalhos na área de Administração, como: Estratégia e Comportamento Organizacional, Marketing e Gestão de Pessoas. Os periódicos com maior número de publicações na área de Administração são: RBGN e BBR.

Para melhor detalhamento e interpretação dos trabalhos que adotaram a entrevista como procedimento de coleta de dados, apresenta-se, no próximo tópico, a análise da preparação e realização das entrevistas.

\subsection{Preparação e Realização das Entrevistas}

Conforme discutido no referencial teórico, a realização de uma entrevista deve ser precedida de uma adequada preparação que inclui pensar em quem entrevistar, o que perguntar, como realizar tais entrevistas e quantas entrevistas serão necessárias para responder adequadamente o problema de pesquisa.

Ao analisar a adoção do "Guia/Roteiro de entrevista", identificou-se que 64 trabalhos utilizaram e evidenciaram seu processo de construção para a condução de suas entrevistas. Entretanto, 103 trabalhos não apresentam seu guia/roteiro nem seus fundamentos teóricos e empíricos. A não discussão e/ou divulgação do guia/roteiro, assim como de seus fundamentos teóricos, comprometem a transparência e confiabilidade da pesquisa e a torna cada vez mais suscetível a críticas, como aponta Gephart (2004). O fato de a maioria dos trabalhos apresentar esse problema metodológico e ainda assim terem sido publicados nos principais periódicos da área demonstram uma possível falha na formação dos editores e avaliadores desses periódicos que também não apontaram tal falha no processo de avaliação dos trabalhos. Outra possibilidade acerca da não discussão e/ou divulgação do guia/roteiro de entrevistas é o 
fato de os periódicos da área estarem restringindo cada vez mais o tamanho dos artigos.

Gendron (2019) alerta sobre o processo e o perigo de os periódicos estarem exigindo cada vez artigos menores por meio de políticas editoriais. Ao estabelecerem limites de páginas restritos, os periódicos acabam colocando em perigo a qualidade dos artigos, principalmente, daqueles de cunho qualitativo que dependem de descrições contextuais ricas e densas (Gendron, 2019). Dentre os periódicos analisados neste trabalho, observa-se que três deles adotam como número máximo de 20 páginas (Contabilidade Vista \& Revista, RUC e RCC), uma aceita até 25 páginas (ASAA), uma define em até 32 páginas, porém com espaçamento duplo, ao contrário das demais que exigem espaçamento simples (RC\&F), enquanto três adotam a política por número de palavras (RCO - entre 4 e 6 mil palavras; $\mathrm{BBR}$ - entre 6 e 8 mil palavras; RBGN - entre 4 e 8 mil palavras).

A importância do guia/roteiro varia de acordo com o tipo de entrevista a ser conduzida, visto que, segundo Kvale (1983), King (2004) e Qu e Dumay (2011), as entrevistas podem ser conduzidas de diferentes maneiras. A estruturada, por exemplo, parte de um roteiro rígido e sem modificações; já as semiestruturadas são conduzidas por um guia mais flexível e as desestruturadas, por sua vez, têm um número reduzido de questões referentes ao tema abordado.

Em seguida, identificou-se, nos procedimentos metodológicos apresentados nas pesquisas, a evidenciação da quantidade de entrevistas realizadas. A Tabela 2 ilustra a média das entrevistas realizadas por periódico investigado, bem como o mínimo e o máximo.

Tabela 2:

Quantidade de entrevistas realizadas

\begin{tabular}{|c|c|c|c|c|c|}
\hline Periódico & Média & Mediana & Moda & Mínimo & Máximo \\
\hline Revista de Contabilidade \& Finanças & 6,66 & 5,00 & 0,00 & 3,00 & 16,00 \\
\hline Revista de Contabilidade \& Organizações & 8,66 & 9,00 & 3,00 & 2,00 & 20,00 \\
\hline Contabilidade Vista \& Revista & 10,50 & 8,00 & 7,00 & 3,00 & 30,00 \\
\hline Revista Universo Contábil & 5,81 & 6,00 & 1,00 & 1,00 & 10,00 \\
\hline Revista Contemporânea de Contabilidade & 4,33 & 4,00 & 4,00 & 1,00 & 12,00 \\
\hline Advances in Scientific and Applied Accounting & 12,00 & 12,00 & 12,00 & 12,00 & 12,00 \\
\hline Brazilian Business Review & 10,03 & 10,00 & 5,00 & 2,00 & 19,00 \\
\hline Revista Brasileira de Gestão de Negócios & 9,84 & 8,00 & 8,00 & 3,00 & 22,00 \\
\hline TOTAL & 8,47 & 8,00 & 5,00 & 1,00 & 141,00 \\
\hline
\end{tabular}

Fonte: dados da pesquisa

No geral, os dados evidenciaram, na amostra analisada, uma média de 8,47 entrevistas realizadas por artigo. Dai, Free e Gendron (2019) identificaram um número médio de 26 entrevistas nos artigos publicados por eles analisados. Ainda, verificaram-se, na amostra analisada, 17 trabalhos que não detalharam a quantidade de entrevistas realizadas. Ressalta-se que a divulgação da quantidade de participantes entrevistados é um critério essencial para a pesquisa qualitativa (Dai, Free \& Gendron, 2019), principalmente no que diz respeito à construção da credibilidade da pesquisa (Messner, Moll \& Strömstem, 2018).

Dos trabalhos analisados, três utilizaram entrevistas conjuntas (grupo focal), indicando os mesmos as justificativas para a escolha dessa modalidade, além de detalharem a forma de realização e análise delas. Importante destacar que somente 14 trabalhos indicaram na metodologia a saturação teórica dos dados. Tais resultados convergem para os achados de Dai, Free e Gendron (2019), os quais indicam que os pesquisadores que utilizam entrevistas devem ser mais cuidadosos ao explicar o desenvolvimento da saturação no decorrer da coleta de dados. Além do número de entrevistas realizadas, é importante considerar a sua qualidade e profundidade. A Tabela 3 apresenta dados relacionados à duração dessas entrevistas.

Tabela 3:

Duração média das entrevistas (minutos)

\begin{tabular}{|c|c|c|c|c|c|}
\hline Periódico & Média & Mediana & Moda & Mínimo & Máximo \\
\hline Revista de Contabilidade \& Finanças & 352,67 & 466,50 & 0,00 & 125,00 & 600,00 \\
\hline Revista de Contabilidade \& Organizações & 68,23 & 240,00 & 0,00 & 30,00 & 600,00 \\
\hline Contabilidade Vista \& Revista & 9,75 & 30,00 & 0,00 & 17,00 & 70,00 \\
\hline Revista Universo Contábil & 14,55 & 45,00 & 0,00 & 25,00 & 160,00 \\
\hline Revista Contemporânea de Contabilidade & 14,32 & 75,00 & 0,00 & 28,00 & 97,50 \\
\hline Advances in Scientific and Applied Accounting & 614,00 & 614,00 & 614,00 & 614,00 & 614,00 \\
\hline Brazilian Business Review & 208,17 & 435,00 & 0,00 & 30,00 & 2500,00 \\
\hline Revista Brasileira de Gestão de Negócios & 359,03 & 640,00 & 0,00 & 175,00 & 2940,00 \\
\hline TOTAL & 205,09 & 337,50 & 0,00 & 25,00 & 2940,00 \\
\hline
\end{tabular}

Fonte: dados da pesquisa 
Diante dos dados dispostos na Tabela 3, foi possível verificar que as entrevistas empreendidas pelos autores para a realização da pesquisa duraram, em média, 3 horas e 25 minutos. Todavia, não se pode afirmar que existe um padrão sobre o tempo de realização das entrevistas, visto que, observando-se os trabalhos que divulgaram a duração, existem entrevistas com 25 minutos e pesquisas que, somando-se o tempo de todas as entrevistas, apresentaram um total de 49 horas. Ao resgatar a Tabela 2, percebe-se que cada periódico apresenta uma média de entrevistas realizadas, o que permite compreender que o número de entrevistas e a duração delas diversificam-se conforme o objetivo dos autores e a amostra disponível. Dessa maneira, observa-se que cada periódico possui sua própria norma social acerca da duração de entrevistas podendo tal norma social estar alinhada com a linha editorial do periódico, as crenças do editor e dos avaliadores.

Ainda sobre a realização das entrevistas, observa-se que: em 64 artigos, as entrevistas foram realizadas presencialmente; dez foram realizadas por "chats de comunicação"; oito foram feitas por telefone; seis utilizaram o e-mail; e os demais trabalhos não apresentam detalhes o suficiente sobre a realização das entrevistas. Dentre as colocações dos autores, a justificativa principal para a realização de entrevistas por outros meios que não presencial estão a localização e a falta de disponibilidade de horário dos entrevistados. Em algumas pesquisas, os autores ressaltaram que foram utilizados mais de um instrumento para a realização da entrevista, porém não foi possível identificar em todos os trabalhos quantas entrevistas foram realizadas por telefone ou presencialmente.

Conforme destaque de Creswell e Creswell (2018), a pesquisa qualitativa apresenta informações sobre os indivíduos e, com isso, a pesquisa, e, consequentemente, a entrevista, deve-se ater a questões que respeitem os envolvidos e o código de ética da área. Para tanto, os comitês e as comissões de ética exercem o papel de avaliar as questões que são a eles submetidas. Dentre os trabalhos analisados, somente três evidenciaram a aprovação pelo comitê de ética ao qual a entrevista foi submetida. O montante de 163 trabalhos não destacou a liberação do comitê ou comissão de ética institucional, não sendo possível, entretanto, afirmar que não houve tal apresentação. Considerando a importância da intencionalidade na escolha dos participantes contida para a realização das entrevistas, foi analisada, complementarmente ao número de entrevistas realizadas, a justificativa para a escolha dos entrevistados.

A justificativa refere-se à análise dos estudos que, de alguma forma, indicaram informações sobre a escolha dos entrevistados em relação ao objetivo da pesquisa. No presente estudo, verificou-se que somente 119 trabalhos apresentaram justificativas relacionadas à escolha dos participantes da pesquisa que concederam as entrevistas. Vale destacar que os estudos que apresentaram as justificativas são breves e não esclarecem detalhes que defendam a escolha dos participantes.

Torna-se relevante apresentar as justificativas referentes à escolha dos entrevistados para a resolução do problema de pesquisa proposto no estudo, visto que toda entrevista é intencional. Verifica-se que 49 trabalhos não indicam nenhuma informação sobre o participante alvo da investigação. Percebe-se que a entrevista é amplamente utilizada, mas verifica-se o despreparo dos pesquisadores para o uso desse procedimento. A literatura alerta que os pesquisadores devem estar preparados e devem deter as habilidade e competências necessárias para a aplicação do método (Hannabuss, 1996; Rubin \& Rubin, 2012; Messner, Moll \& Strömstem, 2018).

Outro aspecto importante no que se refere aos participantes da pesquisa diz respeito às suas características pessoais, profissionais etc., visto que tais características posicionam o participante dentro de um determinado contexto social. Diante disso, também foi analisado se os trabalhos caracterizavam seus participantes. Ao total, foram encontrados 102 trabalhos que caracterizavam os respondentes, enquanto 66 não apresentavam tal discussão.

Importante ressaltar que, dos 102 trabalhos que apresentaram os entrevistados, as informações foram superficiais, ou seja, indicaram, muitas vezes, somente o cargo e/ou o setor da empresa a que estavam vinculados. Além disso, poucos trabalhos caracterizam os entrevistados, considerando a idade, gênero, tempo de experiência na empresa e tempo no cargo atual. Tais informações são importantes para os leitores compreenderem a relação do perfil dos entrevistados com o objeto de análise da pesquisa. A caracterização dos/das participantes da pesquisa é um dos pontos sensíveis da pesquisa realizada com entrevistas, visto que ao mesmo tempo em que apresentar detalhes acerca dos/das participantes é importante para entender como as nuances sociais influenciam os resultados da pesquisa, a apresentação excessiva de detalhes pode colocar em perigo o anonimato dos participantes. Dessa maneira, é preciso que o/a pesquisador(a) reflita sobre esse trade off e inclua os dados necessários e que apresente um equilíbrio entre as nuances da pesquisa e o anonimato dos/das participantes.

O objetivo da entrevista envolve a análise do fenômeno do estudo a partir da perspectiva do participante, que transmite a interpretação dos significados conforme sua percepção do ambiente em que está inserido (King, 2004; Kvale, 2007; Qu \& Dumay, 2011). Dessa forma, conhecer os entrevistados é essencial para a melhor compreensão dos elementos investigados. Vale ressaltar que o acesso ao campo e aos participantes é um aspecto importante na pesquisa qualitativa, visto que isso poderá influenciar na viabilidade da pesquisa (King, 2004).

Outro aspecto importante a ser considerado na apresentação dos participantes da pesquisa e do acesso ao campo é a sensibilidade diante do tema, dado que temas como corrupção, assédio moral e 
sexual, saúde mental, dentre outros, pode colocar em risco a reputação e a trajetória profissional e pessoal do participante. Dentre os trabalhos analisados, destaca-se o trabalho produzido por Medeiros e Freitas Junior (2019), que reconhece a sensibilidade do tema e adota pseudônimos para seus participantes. O uso de pseudônimos para os participantes da pesquisa tem sido encontrado em trabalhos na literatura nacional e internacional de diferentes maneiras. Na literatura nacional, Lima, Vendramin e Casa Nova (2018) adotam como pseudônimos para suas entrevistadas mulheres laureadas pelo Prêmio Nobel com o intuito de trazer mais visibilidade a essas mulheres que, muitas vezes, são silenciadas e/ou esquecidas diante das práticas sexistas da academia de maneiras geral.

Acerca da classificação da abordagem metodológica dos estudos observa-se, na Tabela 4, uma predominância da abordagem qualitativa de pesquisa, como já era esperado. Contudo, observa-se também a presença de 26 trabalhos de cunho misto, 11 estudos que utilizam métodos quantitativos para a análise dos resultados e 03 trabalhos que não se encaixam nessas abordagens, sendo um histórico e um teórico.

Tabela 4:

Abordagens de pesquisa

\begin{tabular}{c|c|c|c|c|c}
\hline Periódico & Quantitativo & Misto & Qualitativo & Indefinido & TOTAL \\
\hline Revista de Contabilidade \& Finanças & 0 & 3 & 6 & 0 & 9 \\
\hline Revista de Contabilidade \& Organizações & 4 & 2 & 15 & 1 & 22 \\
\hline Contabilidade Vista \& Revista & 1 & 3 & 7 & 1 & 12 \\
\hline Revista Universo Contábil & 1 & 3 & 18 & 0 & 22 \\
\hline Revista Contemporânea de Contabilidade & 0 & 1 & 13 & 0 & 14 \\
\hline Advances in Scientific and Applied Accounting & 0 & 0 & 1 & 0 & 1 \\
\hline Brazilian Business Review & 3 & 8 & 31 & 0 & 42 \\
\hline Revista Brasileira de Gestão de Negócios & 2 & 6 & 37 & 1 & 46 \\
\hline TOTAL & $\mathbf{1 1}$ & $\mathbf{2 6}$ & $\mathbf{1 2 8}$ & $\mathbf{3}$ & $\mathbf{1 6 8}$ \\
\hline
\end{tabular}

Fonte: dados da pesquisa

A utilização das entrevistas nas pesquisas de abordagem metodológica mista foi observada de duas maneiras: servindo como uma etapa anterior ao estudo quantitativo, sendo, na maioria das vezes, para o desenvolvimento de instrumentos para survey, ou como uma etapa explicativa para os resultados quantitativos.

Em relação aos trabalhos que foram classificados como quantitativos, observa-se que todos, na verdade, tratavam-se de aplicações de questionários que os autores classificaram como entrevista, demonstrando uma possível desatenção ou falta de conhecimento, tanto dos autores quanto dos avaliadores e editores dos periódicos, visto que as duas abordagens são distintas e o têm vocabulários e nuances próprios. Destaca-se ainda que a utilização de métodos quantitativos para a análise de entrevistas é possível desde que seja realizada de maneira coerente com o objetivo do artigo e a abordagem ontológica, epistemológica e metodológica. Dentre tais possibilidades, existe a $Q$ Methodology aplicada em Contabilidade por Checon (2018) ao analisar o uso de informações contábeis por seus usuários.

Considerando a análise realizada dos trabalhos que utilizaram entrevistas na constituição e análise de evidências das pesquisas, organizou-se a Figura 3 que apresenta nove artigos que atenderam a maioria dos quesitos (categorias) investigados.

\begin{tabular}{|c|c|c|c|}
\hline Revista & Título do Artigo & Autores & Área Temática \\
\hline RUC & $\begin{array}{c}\text { Folga Organizacional: Análise em uma Perspectiva Comportamental no } \\
\text { Campo Empírico }\end{array}$ & Beck e Beuren (2015) & $\begin{array}{l}\text { Contabilidade } \\
\text { Gerencial }\end{array}$ \\
\hline $\mathrm{RCC}$ & $\begin{array}{c}\text { Evidências das Forças Causais Críticas dos Processos de } \\
\text { Institucionalização e Desinstitucionalização em Artefatos da } \\
\text { Contabilidade }\end{array}$ & $\begin{array}{l}\text { Russo, Parisi e Pereira } \\
\text { (2016) }\end{array}$ & $\begin{array}{l}\text { Contabilidade } \\
\text { Gerencial }\end{array}$ \\
\hline $\mathrm{RCC}$ & $\begin{array}{l}\text { A Iniciação Científica na Formação dos Graduandos em Ciências } \\
\text { Contábeis: um estudo em uma Instituição Pública do Triângulo Mineiro }\end{array}$ & Santos e Leal (2014) & $\begin{array}{l}\text { Ensino e Pesquisa } \\
\text { em Contabilidade }\end{array}$ \\
\hline $\mathrm{RCO}$ & $\begin{array}{c}\text { Artificial Ladies Against Corruption: Searching for Legitimacy at the } \\
\text { Brazilian Supreme Audit Institution }\end{array}$ & $\begin{array}{l}\text { Neves, Silva e } \\
\text { Carvalho (2019) }\end{array}$ & Auditoria \& Perícia \\
\hline$B B R$ & Motivações Push e Pull de Brasileiros que amam viajar & $\begin{array}{l}\text { Pereira e Gosling } \\
(2019)\end{array}$ & Outros tópicos \\
\hline$A S A A$ & $\begin{array}{c}\text { Tornando-se professor: análise do processo de construção da Identidade } \\
\text { Docente dos professores de contabilidade }\end{array}$ & Lima e Araújo (2019) & $\begin{array}{l}\text { Ensino e Pesquisa } \\
\text { em Contabilidade }\end{array}$ \\
\hline $\mathrm{RC} \& \mathrm{~F}$ & $\begin{array}{c}\text { Interface dos sistemas de controle gerencial com a estratégia e medidas } \\
\text { de desempenho em empresa familiar }\end{array}$ & Oro e Lavarda (2019) & $\begin{array}{l}\text { Contabilidade } \\
\text { Gerencial }\end{array}$ \\
\hline RBGN & Mulheres empreendedoras no Brasil: quais seus medos? & $\begin{array}{l}\text { Camargo, Lourenço e } \\
\text { Ferreira (2018) }\end{array}$ & Outros tópicos \\
\hline RBGN & $\begin{array}{l}\text { Cultura organizacional e marketing de relacionamento: uma Perspectiva } \\
\text { Interorganizacional }\end{array}$ & $\begin{array}{l}\text { Larentis, Antonello e } \\
\text { Slongo (2018) }\end{array}$ & Outros tópicos \\
\hline
\end{tabular}

Figura 3 - Artigos que apresentaram quesitos essenciais para a análise de entrevistas

Fonte: dados da pesquisa 
Os artigos apresentados no Figura 3 atenderam a evidenciação de quantidade de entrevistas realizadas; a apresentação dos participantes; utilizou citações e análise de trechos das entrevistas; indicou a abordagem adotada no estudo; apresentou a duração das entrevistas e como foram realizadas e, ainda, como foi organizado o guia de entrevista recomendado pela literatura. Os trabalhos apresentam boas práticas no uso de entrevistas no trabalho científico.

A partir dos resultados apresentados observa-se que as normas sociais encontradas nos periódicos brasileiros se diferenciam em diversos aspectos das normas encontradas por Dai, Free e Gendron (2019). Esse resultado é suportado pela Sociologia do Conhecimento, visto que segundo Berger e Luckmann (2014) cada comunidade determina o que torna válido ou inválido determina forma de conhecimento. Observou-se ainda que algumas das normas sociais na amostra analisada se diferem de periódico a periódico, como é o caso da quantidade e duração de entrevistas, demonstrando que a linha editorial, assim como a figura do editor e os avaliadores influenciam a construção do conjunto de normas sociais.

\section{Considerações Finais}

O artigo teve como objetivo visa analisar o emprego de entrevistas na constituição de evidências na pesquisa contábil brasileira. Para isso, foram analisados 168 artigos de oito periódicos científicos de Contabilidade classificados como A2 segundo o Qualis Capes. É importante destacar que a presente pesquisa não visa construir e apresentar um check-list de como se publicar uma pesquisa cujo corpus foi constituído por entrevistas.

Ao contrastar os resultados da pesquisa com os resultados de Dai, Free e Gendron (2019) observase que as normas sociais que permeiam o uso de entrevistas nos periódicos brasileiros diferem-se das normas adotadas por periódicos de língua inglesa. Esse resultado é suportado pela Sociologia do Conhecimento, visto que há "diferenças observáveis entre as sociedades em termos daquilo que é admitido como 'conhecimento' nelas" (Berger \& Luckmann, 2014, p. 13). Um resultado importante acerca da pesquisa brasileira refere-se à falta de transparência dos processos envolvidos na pesquisa, dado que diversos trabalhos não apresentam como construíram seu guia/roteiro de entrevista, como foram realizadas as entrevistas, bem como não evidenciaram maiores detalhes acerca delas. Tal resultado pode indicar a necessidade de melhor formação dos atores sociais envolvidos na elaboração e publicação da pesquisa qualitativa no Brasil (autores/as, editores/as e avaliadores/as) ou ser consequência do processo de redução do tamanho dos artigos que os periódicos têm passado como discute Gendron (2019).

Destaca-se ainda a pouca diversidade das estratégias de análise do corpus, o que pode ser decorrente do pouco treinamento formal dos pesquisadores da área. É importante também ressaltar que, durante a construção da base de artigos a serem analisados, foram encontrados artigos que adotavam o termo "entrevistas" e/ou "entrevistados" de maneira equivocada e sendo aplicados, na realidade, às pesquisas do tipo survey.

Quanto à apresentação dos entrevistados, foram identificadas informações superficiais presentes nos artigos investigados. Torna-se relevante a apresentação dos entrevistados participantes da pesquisa com maior detalhamento, visto que tais dados auxiliam na interpretação dos significados apresentados pelo entrevistado conforme o ambiente em que está inserido. Ao mesmo tempo tal questão se coloca como trade off entre as nuances da pesquisa e o anonimato dos/das participantes exigindo uma postura reflexiva do/da pesquisador/a.

Torna-se relevante destacar também a baixa evidenciação nos trabalhos sobre a saturação teórica dos dados, alertando aos pesquisadores que, quando adotarem o procedimento de entrevistas, é importante indicar o processo de saturação no decorrer da coleta de dados. Outro elemento negligenciado pelos pesquisadores diz respeito às questões éticas, tanto quanto a apreciação de comissões de ética e/ou o breve consentimento de participação na pesquisa e, especificamente, nas entrevistas.

Entende-se que o presente estudo contribui para a reflexão de pesquisadores/as, editores/as e avaliadores/as de periódicos acerca dos aspectos metodológicos adotados nas pesquisas qualitativas, especialmente, sobre a aplicação da entrevista. Ademais, a pesquisa colabora com pesquisadores/as interessados em conduzir entrevistas para que conheçam os principais critérios metodológicos indicados para a preparação, condução e interpretação. Dessa forma, pesquisadores/as poderão cooperar para 0 aprimoramento da pesquisa qualitativa na área contábil. Por fim, o presente trabalho apresenta as normas sociais adotadas pela comunidade contábil brasileira na adoção das entrevistas, podendo tais normas refletirem aspectos culturais da nossa comunidade, como esperado de acordo com a Sociologia do Conhecimento.

Como limitação, o presente trabalho analisa apenas oito periódicos da área de Contabilidade. Assim, pode ser que outros periódicos contenham artigos com maior pluralidade nas análises de dados e maior transparência nos processos. É importante também ressaltar que, dos oito periódicos, dois possuem grande interface com a área de administração, o que pode influenciar os resultados e as interpretações. Por fim, destaca-se que o presente artigo não diferencia as tradições de pesquisa (positivismo, interpretativismo, pesquisa crítica), sendo que as normas sociais podem ser diferentes para cada uma dessas comunidades, visto que elas diferem ontologicamente e epistemologicamente, ou seja, entendem a realidade e a 
construção do conhecimento de maneira diferente.

Para pesquisas futuras, considerando as contribuições da abordagem qualitativa e a qualidade das informações coletadas e analisadas, sugere-se uma revisão estruturada da literatura publicada para verificação de sua contribuição de forma independente e/ou complementar à abordagem quantitativa na área contábil. Aconselha-se ainda a análise aprofundada dos artigos que empregam a técnica de análise de conteúdo, visando desvelar as práticas sociais acerca dessa metodologia de análise. Sugere-se também a elaboração de artigos que discutem e apresentam as potencialidades de outras estratégias de análise qualitativa, assim como entrevistar os atores sociais envolvidos no processo de construção das normas sociais acerca das entrevistas para melhor compreender o processo de construção e consolidação dessas.

\section{Referências}

Barreto, E., Murcia, F. D. R., \& Lima, I. S. (2012). Impacto da mensuração a valor justo na crise financeira mundial: Identificando a percepção de especialistas em economia e mercado financeiro. Revista De Contabilidade E Organizações, 6(15), 44-59. https://doi.org/10.11606/rco.v6i15.52656

Beck, F., \& Beuren, I.M. (2015). Folga organizacional: análise em uma perspectiva comportamental no campo empírico. Revista Universo Contábil, 11(4), 06-26. https://doi.org/10.4270/ruc.2015429

Berg, B.L. (1998). Qualitative Research Methods for the Social Sciences, Allyn and Bacon, Boston, MA.

Berger, P. L. \& Luckmann, T. (2014). A construção social da realidade: tratado de sociologia do conhecimento. Editora Vozes.

Berger, R. (2015). Now I see it, now I don't: Researcher's position and reflexivity in qualitative research. Qualitative research, 15, 219-234. https://doi.org/10.1177/1468794112468475

Burrell, G., \& Morgan, G. (1979). Sociological Paradigms and Organization Analysis. London: Heinemann.

Camargo, R. A. M. M., Lourenço, M. L., \& Ferreira, J. M. (2018). Mulheres Empreendedoras no Brasil: Quais seus Medos? Revista Brasileira de Gestão de Negócios, 20(2), 178-193. https://doi.org/10.7819/rbgn.v20i2.3578

Checon, B. Q. (2018). Limited attention, the use of accounting information and its impacts on individual investment decision making. Tese de Doutorado, Faculdade de Economia, Administração e Contabilidade, Universidade de São Paulo, São Paulo. DOI: https://doi.org/10.11606/T.12.2018.tde-24082018-153805

Creswell, J. (2012). Qualitative inquiry \& Research design: choosing among five approaches. Thousand Oaks: SAGE Publications.

Creswell, J. W. (2015). A concise introduction to mixed methods research. Thousand Oaks, CA: Sage.

Creswell, J. W., \& Creswell J. D. (2018). Research design: qualitative, quantitative and mixed methods approaches. Los Angeles: Sage Publications.

Crotty, M. (1998). Introduction: The Research Process. In: The foundations of social research: Meaning and perspective in the research process. Sage.

Cunliffe, A. L., \& Alcadipani, R. (2016). The politics of access in fieldwork: Immersion, backstage dramas, and deception. Organizational Research Methods, 19(4), 535-561. https://doi.org/10.1177/1094428116639134

Dai, N. T., Free, C., \& Gendron, Y. (2019). Interview-based research in accounting 2000-2014: Informal norms, translation and vibrancy. Management Accounting Research, 42, 26-38. https://doi.org/10.1016/i.mar.2018.06.002

Dambrin, C., \& Lambert, C. (2012). Who is she and who are we? A reflexive journey in research into the rarity of women in the highest ranks of accountancy. Critical Perspectives on Accounting, 23(1), 1-16. https://doi.org/10.1016/j.cpa.2011.06.006

Deakin, H., \& Wakefield, K. (2014). Skype interviewing: reflections of two PhD researchers. Qualitative Research, 14(5), 603-616. https://doi.org/10.1177/1468794113488126 
Denzin, N. K., \& Lincoln, Y. S. (2005). The Sage handbook of qualitative research. Sage.

Diehl, A. A., \& Tatim, D. C. (2004). Pesquisa em ciências sociais aplicadas: métodos e técnicas. Pearson Brasil.

Douglas, J. D. (1985). Creative Interviewing, Sage, Beverly Hills, CA.

Doyle, J. K. (2004). Introduction to interviewing techniques, In Wood, D.W. (Ed.), Handbook for IQP Advisors and Students, Worcester Polytechnic Institute, Worcester, MA.

Dyckman, T. R., \& Zeff, S. A. (2015). Accounting research: past, present, and future. Abacus, 51(4), 511524. https://doi.org/10.1111/abac.12058

Eriksson, P., \& Kovalainen, A. (2008). Qualitative Methods in Business Research, Sage, London. https://doi.org/10.4135/9780857028044

Espejo, M. M. dos S. B., \& Von Eggert, N. S. (2017). Não deu certo por quê? Uma aplicação empírica da extensão do modelo de Burns e Scapens no âmbito da implementação de um departamento de controladoria. Revista Contabilidade \& Finanças, 28(73), 43-60. https://doi.org/10.1590/1808$\underline{057 \times 201702820}$

Eysenbach, G., \& Till, J. E. (2001). Ethical issues in qualitative research on internet communities. BMJ, 323(7321), p. 1103-1105. https://doi.org/10.1136/bmj.323.7321.1103

Fairclough, N., \& Melo, I. F. de. (2012). Análise Crítica do Discurso como método em pesquisa social científica. Linha D’Água, 25(2), 307-329. https://doi.org/10.11606/issn.2236-4242.v25i2p307-329

Flick, U. (2013). Introdução à metodologia de pesquisa: um guia para iniciantes. Penso Editora.

Fontana, A., \& Frey, J.H. (1998). "Interviewing, the art of science", in Denzin, N.K. and Lincoln, Y.S. (Eds), Collecting and Interpreting Qualitative Materials, Sage, Thousand Oaks, CA.

Foucault, M. (2008). A Arqueologia do Saber. (7ª ed.). Rio de Janeiro, RJ: Forense Universitária.

Ganz, A. C. S., Lima, J. P. R., \& Haveroth, J. (2019). Velhos Problemas, Novos Olhares: Etnografia sobre a Experiência de Futuros Doutores em Contabilidade. Anais do USP International Conference in Accounting, 19., 2019, São Paulo.

Gendron, Y. (2019). Mantendo-se fiel ao contexto. Sociedade, Contabilidade e Gestão, v. 14, n. 4, 80-95. https://doi.org/10.21446/scg ufri.v14i4.31345

Gephart Jr, R. P. (2004). Qualitative research and the Academy of Management Journal. Academy of Management Journal, 47(4), 454-462. https://doi.org/10.5465/amj.2004.14438580

Godoi, C. K. (2010). Perspectivas de análise do discurso nos estudos organizacionais. In: Silva, A. B., Godoi, C.K., \& Bandeira-de-Mello, R. (Org). Pesquisa qualitativa em estudos organizacionais: paradigmas, estratégias e métodos. São Paulo: Saraiva.

Godoy, A. S. (2018). Reflexão a respeito das contribuições e limites da história de vida na pesquisa em Administração. Administração: Ensino e Pesquisa, 19(1), 161-175. https://doi.org/10.13058/raep.2018.v19n1.954

Golden-Biddle, K., \& Locke, K. (1993). Appealing works: an investigation of how ethnographic texts convince. Organization Science, 4(4), 595-616. https://doi.org/10.1287/orsc.4.4.595

Greene, J. (1998). Qualitative program evaluation, practice and promise, in Denzin, N. K., \& Lincoln, Y. S. (Eds), Collecting and Interpreting Qualitative Materials, Sage, Thousand.

Gubrium, J. F., Holstein, J. A., Marvasti, A. B., \& MCkinney, K. D. (2012). (Eds.). The SAGE handbook of interview research: The complexity of the craft. Sage Publications. https://doi.org/10.4135/9781452218403

Hanna, P. (2012). Using internet technologies (such as Skype) as a research medium: a research note. Qualitative Research, 12(2), 239-242. https://doi.org/10.1177/1468794111426607 
Hannabuss, S. (1996). Research interviews, New Library World, 97(1129), 22-30. https://doi.org/10.1108/03074809610122881

Hardy, C. (2001). Researching organizational discourse. International Studies of Management \& Organization, 31(3), p. 25-47. https://doi.org/10.1080/00208825.2001.11656819

Hay-Gibson, N. V. (2009). Interviews via VolP: Benefits and disadvantages within a PhD study of SMEs. Library and Information Research, 33(105), 39-50. https://doi.org/10.29173/lirg111

Haynes, K. (2006). Linking narrative and identity construction: using autobiography in accounting research. Critical Perspectives on Accounting, 17(4), 399-418. https://doi.org/10.1016/i.cpa.2004.08.005

Haynes, K. (2010). Other lives in accounting: critical reflections on oral history methodology in action. Critical Perspectives on Accounting, 21(3), 221-231. https://doi.org/10.1016/i.cpa.2009.11.002

Horton, J., Macve, R., \& Struyven, G. (2004). Qualitative research: experiences in using semi-structured interviews. In The real life guide to accounting research. Elsevier. 339-357. https://doi.org/10.1016/B978$\underline{008043972-3 / 50022-0}$

Huff, A. S. (1999). Writing for scholarly publication. Sage.

ludícibus, S., Martins, E., \& Carvalho, L. N. (2005). Contabilidade: Aspectos Relevantes. Revista de Contabilidade e Finanças, 20(38), 7-19. https://doi.org/10.1590/S1519-70772005000200002

Jaime Junior, P. (2003). Pesquisa em organizações: por uma abordagem etnográfica. Civitas - Revista de Ciências Sociais, 3(2), 435-456. https://doi.org/10.15448/1984-7289.2003.2.129

Kihn, L. A., \& Ihantola, E. M. (2015). Approaches to validation and evaluation in qualitative studies of management accounting. Qualitative Research in Accounting \& Management, 12(3), 230-255. https://doi.org/10.1108/QRAM-03-2013-0012

Kincheloe, J. L. (2011). Describing the bricolage: Conceptualizing a new rigor in qualitative research. In Key works in critical pedagogy. Brill Sense. 177-189. https://doi.org/10.1007/978-94-6091-397-6 15

King, N. (2004). Using interviews in qualitative research. In: Cassel, C. \& Symon, G. Essential guide to qualitative methods in organizational research. Londres: Sage Publications. 11-22. https://doi.org/10.4135/9781446280119.n2

Kvale, S. (2007). Doing Interviews, Sage, London. https://doi.org/10.4135/9781849208963

Kvale, S. (1983). The qualitative research interview: A phenomenological and a hermeneutical mode of understanding. Journal of Phenomenological Psychology, 14(2), 171. https://doi.org/10.1163/156916283X00090

Larentis, F., Antonello, C. S., \& Slongo, L. A. (2018). Cultura Organizacional e Marketing de Relacionamento: Uma Perspectiva Interorganizacional. Revista Brasileira de Gestão de Negócios, 20(1), 3756. DOI: https://doi.org/10.7819/rbgn.v20i1.3688

Lillis, A. (2006). Reliability and validity in field study research, in Hoque, Z. (Ed.), Methodological Issues in Accounting Research: Theories and Methods, Spiramus, London. 461-475.

Lima, J. P. R. De., Vendramin, E. De O., \& Casa Nova, S. P. de C. (2018). Identidade acadêmicas em uma era de produtivismo: o (des)alojamento das mulheres contadoras. Anais do ANPAD, 2018, Rio de Janeiro.

Lima, J., \& Araujo, A. (2019). Tornando-se professor: análise do processo de construção da Identidade Docente dos professores de Contabilidade. Advances in Scientific and Applied Accounting, 1(2), 059-080. https://doi.org/10.14392/ASAA.2019120204

Lima, T. C. S. De., \& Mioto, R. C. T. (2007). Procedimentos metodológicos na construção do conhecimento científico: a pesquisa bibliográfica. Revista Katálysis, 10, 37-45. https://doi.org/10.1590/S1414$\underline{49802007000300004}$ 
Lincoln, Y.S., \& Guba, E.G. (1985). Naturalistic Inquiry, Sage, Beverly Hills, CA. https://doi.org/10.1016/0147-1767(85)90062-8

Lukka, K., \& Kasanen, E. (1995). "The problem of generalizability: anecdotes and evidence in accounting research", Accounting, Auditing \& Accountability Journal, 8(5), 71-90. https://doi.org/10.1108/09513579510147733

Lune, H., \& Berg, B. L. (2017). Qualitative research methods for the social sciences. Pearson Higher Ed.

Mahama, H., \& Khalifa, R. (2017). Field interviews. In: Hoque, Z.; Parker, L. D.; Covaleski, M. A., \& Haynes, K. (Org). The Routledge companion to qualitative accounting research methods. 321-338.

Major, M. J. (2017). O positivismo e a pesquisa 'alternativa' em Contabilidade. Revista Contabilidade \& Finanças, 28(74), 173-178. https://doi.org/10.1590/1808-057x201790190

Mäkinen, V. (1980). Approaches to researching a company's operations. Development of a business analytical research strategy, University of Tampere, Publications of the Department of Business Economics and Private Law,1-17.

Malsch, B., \& Salterio, S. E. (2016). Doing Good Field Research: Assessing the Quality of Audit Field Research. Auditing: A Journal of Practice \& Theory, 35(1), 1-22. https://doi.org/10.2308/ajpt-51170

Malsch, B., \& Tessier, S. (2015). Journal ranking effects on junior academics: Identity fragmentation and politicization. Critical Perspectives on Accounting, 26, 84-98. https://doi.org/10.1016/j.cpa.2014.02.006

Martins, E. A. (2012). Pesquisa contábil brasileira: uma análise filosófica. 2012. Tese (Doutorado) Curso de Pós-Graduação, Faculdade de Economia, Administração e Contabilidade, Universidade de São Paulo, São Paulo. DOI: https://doi.org/10.11606/T.12.2012.tde-14022013-171839

Martins, E. (2005). Editorial: normativismo e/ou positivismo em contabilidade: qual o futuro? Revista Contabilidade \& Finanças, 16(39), 3-3. https://doi.org/10.1590/S1519-70772005000300001

Mattos, P. L. C. L. de. (2011). Os resultados desta pesquisa (qualitativa) não podem ser generalizados: pondo os pingos nos is de tal ressalva. Cadernos EBAPE.BR, 9(1), 450-468. https://doi.org/10.1590/S1679$\underline{39512011000600002}$

Mayring, P. (2000). Qualitative Content Analysis. In: Flick, U.; Von Kardoff, E.; Steinke I. (Eds). A companion to qualitative research. New Delhi: Sage Publications.

Mclntosh, M. J., \& Morse, J. M. (2015). Situating and Constructing Diversity in Semi-Structured Interviews. Global Qualitative Nursing Research. https://doi.org/10.1177/2333393615597674

Medeiros, C. R. de O., \& Freitas Júnior, L. R. de. (2019). Padrões discursivos sobre corrupção. Revista de Contabilidade e Organizações, 13, e152220. https://doi.org/10.11606/issn.1982-6486.rco.2019.152220

Merchant, K. A. (2010). Paradigms in accounting research: A view from North America. Management Accounting Research, 21(2), 116-120. https://doi.org/10.1016/..mar.2010.02.004

Merriam, S. (2002). Basic interpretive qualitative research. In: Merriam, S. (Org). Qualitative Research in Practice: Examples for Discussion and Analysis. (pp. 37-39).

Messner, M., Moll, J., \& Strömsten, T. (2018). Credibility and Authenticity in Qualitative Accounting Research. IN: Hoque, Z.; Parker, L.; Covaleski, M. A. \& Haynes K. (Org). The Routledge Companion to Qualitative Accounting Research Methods. (pp. 432- 444).

Morgan, S.J., \& Symon, G. (2004). Electronic Interviews in Organisational Research, in C. Cassell and G.Symon (eds) Essential Guide to Qualitative Methods in Organisational. https://doi.org/10.4135/9781446280119.n3

Mozzato, A. R., \& Grzybovski, D. (2011). Análise de conteúdo como técnica de análise de dados qualitativos no campo da administração: potencial e desafios. Revista de Administração Contemporânea, 15(4), 731747. https://doi.org/10.1590/S1415-65552011000400010 
Muylaert, C. J., Sarubbi JR, V., Gallo, P. R., Neto, M. L. R., \& Reis, A. O. A. (2014). Narrative interviews: an important resource in qualitative research. Revista da Escola de Enfermagem da USP, 48(2), 184-189. https://doi.org/10.1590/S0080-623420140000800027

Näsi, J. (1979). The basics of business planning. Conceptual methodological structures and philosophical background of science. [English Summary: The Basis of Corporate Planning], University of Tampere, Publications of the Department of Business Economics and Private Law Series A. 1-15.

Neves, F. R., da Silva, P. B., \& Carvalho, H. L. M. de. (2019). Mulheres artificiais contra a corrupção: em busca de legitimidade no Tribunal de Contas da União. Revista de Contabilidade e Organizações, 13, 31-50. https://doi.org/10.11606/issn.1982-6486.rco.2019.158530

Newman, I., \& Benz, C. R. (1998). Qualitative-quantitative research methodology: Exploring the interactive continuum. Carbondale and Edwardsville: Southern Illinois University Press.

O'Connor H., Madge C., Shaw R., \& Wellens J. (2008). Internet-based interviewing. In: Fielding N, Lee and Blank G (eds) The SAGE Handbook of Online Research Methods. London: Sage. 271-289. https://doi.org/10.4135/9780857020055.n15

O'Connor, H., \& Madge, C. (2004). Cyber-mothers: online synchronous interviewing using conferencing software. Sociological Research Online, 5(4). https://doi.org/10.1177/136078040400900205

Opdenakker, R. (2006). Advantages and disadvantages of four interview techniques in qualitative research. Forum: Qualitative Social Research, 7(4). https://doi.org/10.17169/fqs-7.4.175

Orb, A., Eisenhauer, L., \& Wynaden, D. (2001). Ethics in qualitative research. Journal of nursing scholarship, 33(1), 93-96. https://doi.org/10.1111/i.1547-5069.2001.00093.x

Oro, I. M., \& Lavarda, C. E. F. (2019). Interface dos Sistemas de Controle Gerencial com a Estratégia e Medidas de Desempenho em Empresa Familiar. Revista Contabilidade \& Finanças - USP, 30(79), 14-27. https://doi.org/10.1590/1808-057×201806490

Pagliarussi, M. (2018). Estrutura e redação de artigos em contabilidade e organizações. Revista de Contabilidade e Organizações, 11(31), 4-10. https://doi.org/10.11606/rco.v11i31.142547

Paiva Júnior, F. G., Leão, A. L. M. S., \& De Mello, S. C. B. (2011). Validade e confiabilidade na pesquisa qualitativa em administração. Revista de Ciências da Administração, 13(31), 190-209. https://doi.org/10.5007/2175-8077.2011v13n31p190

Pentland, B. T. (1999). Building process theory with narrative: From description to explanation. Academy of management Review, 24(4), 711-724. https://doi.org/10.5465/amr.1999.2553249

Pepitone, A. (1976). Toward a normative and comparative biological cultural social psychology. Journal of Personality and Social Psychology, 34, 641-653. https://doi.org/10.1037/0022-3514.34.4.641

Pereira, G. A., \& Gosling, M. (2019). Motivações push e pull de brasileiros que amam viajar. BBR, Braz. Bus. Rev. [online]. 16(1), 63-86. https://doi.org/10.15728/bbr.2019.16.1.5

Qu, S., \& Dumay, J. (2011). The qualitative research interview. Qualitative Research in Accounting \& Management, 8(3), 238-264. https://doi.org/10.1108/11766091111162070

Richardson, A. J. (2015). Quantitative research and the critical accounting project. Critical Perspectives on Accounting, 32, 67-77. https://doi.org/10.1016/j.cpa.2015.04.007

Rubin, H. J., \& Rubin, I. S. (2012). The art of hearing data. Thousand Oaks.

Russo, P. T., Parisi, C., \& Pereira, C. A. (2016). Evidências das Forças Causais Críticas dos Processos de Institucionalização e Desinstitucionalização em Artefatos da Contabilidade Gerencial. Revista Contemporânea de Contabilidade, 13(30), 3-33. https://doi.org/10.5007/2175-8069.2016v13n30p3

Ryan, B., Scapens, R.W., \& Theobald, M. (2002). Research Method and Methodology in Finance and Accounting, 2 ed., Thomson, London. 
Saccol, A. Z. (2009). Um retorno ao básico: compreendendo os paradigmas de pesquisa e sua aplicação na pesquisa em administração. Revista de Administração da UFSM, 2(2), 250-269. https://doi.org/10.5902/198346591555

Santos, C. K. S., \& Leal, E. A. (2014). A iniciação científica na formação dos graduandos em ciências contábeis: um estudo em uma instituição pública do triângulo mineiro. Revista Contemporânea de Contabilidade, 11(22), 25-48. https://doi.org/10.5007/2175-8069.2014v11n22p25

Schensul, J. J., \& Lecompte, M. D. (2012). Essential ethnographic methods: A mixed methods approach. 3. Rowman Altamira.

Seidman, I. (2006). Interviewing as qualitative research: A guide for researchers in education and the social sciences. Nova York: Teachers college press.

Seitz, S. (2016). Pixilated partnerships, overcoming obstacles in qualitative interviews via Skype: A research note. Qualitative Research, 16(2), 229-235. https://doi.org/10.1177/1468794115577011

Serva, M., \& Jaime Júnior, P. (1995). Observação participante pesquisa em administração: uma postura antropológica. Revista de Administração de Empresas, 35(3), 64-79. https://doi.org/10.1590/S0034$\underline{75901995000300008}$

Sherif, M. (1936). The psychology of social norms. New York: Harper.

Silva, C. D. N. (2015). Conte comigo! Características da consultoria contábil aos pequenos negócios. Dissertação de Mestrado, Faculdade de Economia, Administração e Contabilidade, Universidade de São Paulo, São Paulo. doi: https://doi.org/10.11606/D.12.2016.tde-18012016-161033

Silva, S. M. C. D., \& Nova, S. P. D. C. C. (2018). Pesquisa qualitativa ou qualidade em pesquisa? Um exemplo de contribuição sócio humanista em pesquisa contábil. Sociedade, Contabilidade e Gestão, 13(1), 120-141. https://doi.org/10.21446/scg ufrj.v13i1.15860

Smith, M. (2003). Research methods in accounting. SAGE Publications Limited. https://doi.org/10.4135/9781849209809

Soares Neto, A., \& Da Silva, A. B. (2012). Os estágios de aprendizagem de auditores fiscais no contexto da prática profissional. Revista de Administração Pública-RAP, 46(3), 841-863. https://doi.org/10.1590/S0034$\underline{76122012000300011}$

Stenbacka, C. (2001). Qualitative research requires quality concepts of its own. Management decision, 39(7), 551-556. https://doi.org/10.1108/EUM0000000005801

Van Dijk, T. A. (1993). Principles of critical discourse analysis. Discourse \& society, 4(2), 249-283. https://doi.org/10.1177/0957926593004002006

Veiga, H. M. D. S., Torres, C. V., \& Bruno-Faria, M. D. F. (2013). Comportamento pró-ativo e normas sociais: validação de medidas e estudo correlacional. Revista Psicologia Organizações e Trabalho, 13(2), 155-170.

Yin, R.K. (2009). Case Study Research Design and Methods. (4 ed.). Sage Publications, Thousand Oaks.

Zaccarelli, L. M., \& Godoy, A. S. (2014). Deixa eu te contar uma coisa...: Possibilidades do uso de narrativas e sua análise nas pesquisas em organizações. Revista Gestão Organizacional, 6(3). https://doi.org/10.22277/rgo.v6i3.1521

\section{NOTAS}

\section{AGRADECIMENTOS}

Agradecimentos ao CNPq e FAPEMIG pelo apoio ao projeto de pesquisa.

\section{CONTRIBUIÇÃO DE AUTORIA}

Concepção e elaboração do manuscrito: J. P. R. Lima, V. R. Silva, E. A. Leal

Coleta de dados: J. P. R. Lima, V. R. Silva, E. A. Leal

Análise de dados: J. P. R. Lima, V. R. Silva, E. A. Leal 
Discussão dos resultados: J. P. R. Lima, V. R. Silva, E. A. Leal

Revisão e aprovação: J. P. R. Lima, V. R. Silva, E. A. Leal

CONJUNTO DE DADOS DE PESQUISA

Todo o conjunto de dados que dá suporte aos resultados deste estudo foi publicado no próprio artigo.

\section{FINANCIAMENTO}

Não se aplica.

\section{CONSENTIMENTO DE USO DE IMAGEM}

Não se aplica.

\section{APROVAÇÃO DE COMITÊ DE ÉTICA EM PESQUISA}

Não se aplica.

\section{CONFLITO DE INTERESSES}

Não se aplica.

\section{LICENÇA DE USO}

Os Direitos Autorais para artigos publicados neste periódico são do autor, com direitos de primeira publicação para a Revista. Em virtude de aparecerem nesta Revista de acesso público, os artigos são de uso gratuito, com atribuições próprias, em aplicações educacionais, de exercício profissional e para gestão pública. A Revista adotou a licença Creative Commons Atribuição 4.0 Internacional - CC BY NC ND. Esta licença permite acessar, baixar (download), copiar, imprimir, compartilhar, reutilizar e distribuir os artigos desde que com a citação da fonte, atribuindo os devidos créditos de autoria. Nesses casos, nenhuma permissão é necessária por parte dos autores ou dos editores. Autores têm autorização para assumir contratos adicionais separadamente, para distribuição não-exclusiva da versão do trabalho publicada nesta revista (ex.: publicar em repositório institucional ou um capítulo de livro).

\section{PUBLISHER}

Universidade Federal de Santa Catarina. Curso de Ciências Contábeis e Programa de Pós-graduação em Contabilidade. Publicação no Portal de Periódicos UFSC. As ideias expressadas neste artigo são de responsabilidade de seus autores, não representando, necessariamente, a opinião dos editores ou da universidade.

\section{EDITORES}

Carlos Eduardo Facin Lavarda e Suliani Rover

\section{HISTÓRICO}

Recebido em: 29/08/2020 - Revisado por pares em: 10/02/2021 - Reformulado em: 24/05/2021 Recomendado para publicação em: 21/07/2021 - Publicado em: 04/10/2021 